\title{
Biochemical, Anti-Diarrhoeal and Anti-Gastric Ulcer Activities of Commiphora myrrha
}

\author{
Mohammad Kamil* and TM Abdalla \\ Department of Health, Division of Healthcare Licensing \& Medical Education, Abu Dhabi, UAE
}

*Corresponding author: Mohammad Kamil, Zayed Complex-for Herbal Research \& Traditional Medicine, Division of Healthcare Licensing \& Medical Education, Department of Health, Abu Dhabi, UAE

\begin{tabular}{|c|c|}
\hline ARTICLE INFO & ABSTRACT \\
\hline Received: 慧 July 03, 2019 & Citation: Mohammad Kamil, TM Abdalla. Biochemical, Anti-Diarrhoeal and Anti-Gastric \\
\hline Published: 慧 July 09, 2019 & $\begin{array}{l}\text { Ulcer Activities of Commiphora myrrha. Biomed J Sci \& Tech Res 19(3)-2019. BJSTR. } \\
\text { MS.ID.003306. }\end{array}$ \\
\hline
\end{tabular}

\section{Introduction}

Myrrh is a spiny, deciduous shrub or small tree growing about 5 meters tall. It usually has a small but distinct bole. An oleo-resin gum exudes from the bark of this species and various other members of the Commiphora genus, (Encyclopedia of Herbs and their Uses Bown. D. 1995, ISBN: 0-7513-020- 31, Dorling Kindersley, London) (Figure 1).

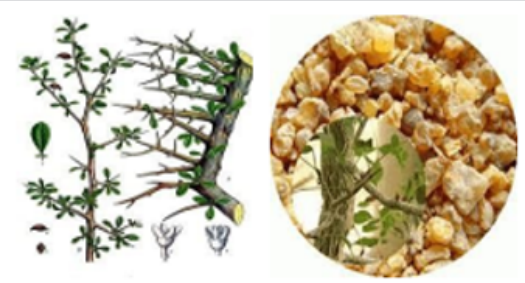

\begin{tabular}{|c|c|}
\hline Scientific Name & Commiphora myrrha var. molmol Engl \\
\hline Synonyms & Commiphora myrrha (Nees) Engl. \\
\hline English Name & myrrha, gum myrrh, common myrrh; (Somali: didin) \\
\hline Arabic Name & Al Murr \\
\hline Common Name & Myrrh \\
\hline Family & Burseraceae \\
\hline
\end{tabular}

Figure 1: Commiphora myrrha.

\section{Habitat and Distribution}

Thickets in desert scrubland (Encyclopaedia of Herbs and their Uses. Description Open Acacia, Commiphora bushland on shallow soil, chiefly over limestone at elevations from 250-1,300 meters. Eastern and northeastern Tropical Africa-Ethiopia, Somalia, Kenya; Arabian Peninsula-Saudi Arabia, Oman.

\section{Medicinal Activity}

The resin obtained from the bark of myrrh is a pungent, astringent, aromatic herb that is strongly stimulant, antiseptic and expectorant. Myrrh is used externally to treat mouth ulcers, wounds, boils, and is often added to oral preparations. An essential oil obtained from the resin is used by aroma-therapists as a natural antiseptic for treating skin and mouth problems. It was observed that there a significant difference in the Cmax, AUC, AUMC, $t_{1 / 2}$ and MRT of theophylline when co-administered with Commiphora myrrha which indicate that the herb affects the metabolism and elimination when co-administered with theophylline [1]. Guggul gum resin from Commiphora wightii (syn. Commiphora mukul) has been used for centuries in Ayurveda to treat a variety of ailments [2].

The Commiphora resins possess anti-inflammatory and antitumor activity Antibacterial and antifungal bioassay shows antibacterial and antifungal activity higher in the myrrha oil than the Africana oil while antiviral bioassay shows higher antiviral activity in the Africana oil than myrrha oil [3]. Myrrh ("Morr" in Persian) is a yellow-brown aromatic oleo-gum resin obtained from the stems of the genus Commiphora, particularly C. myrrha (Burseraceae). It has been demonstrated that myrrh has broad spectrum of biological properties including antibacterial, antinociceptive, anti- inflammatory and anti-ulcer activities. Moreover, it has been reported that myrrh has antioxidant and immune potentiating properties [4].

\section{Known Hazards}

This herb is contra-indicated during pregnancy because of its emmenagogue activity. It is advisable to dilute myrrh before use and 
administer moderate doses. Allergic reactions have been observed.

The below Pharmacological Studies Carried out on the Aqueous Extract of the Plant Commiphora myrrha at ZCHRTM Labs. [5,6]:

\section{The Analgesic Activity:}

The Analgesic Activity effects of Commiphora myrrha was carried out using Mice model and Hot plate method, it showed negative analgesic effect.

\section{Anti-diarrhoeal Activity:}

The Anti-diarrheal activity of Commiphora myrrha was studied using castor oil to induce diarrhea in mice model resulted in positive anti-diarrheal effect (Figure 2).

\section{Biochemical Studies:}

Commiphora myrrh studied at a dose of $1 \mathrm{~g} / \mathrm{kg} / 15$ days p.o. on SD rats showed no significant changes on Biochemical parameters: ALB, ALP, BUN, CHOL, GLU, AST, ALT, LDH and TP (Figure 3).

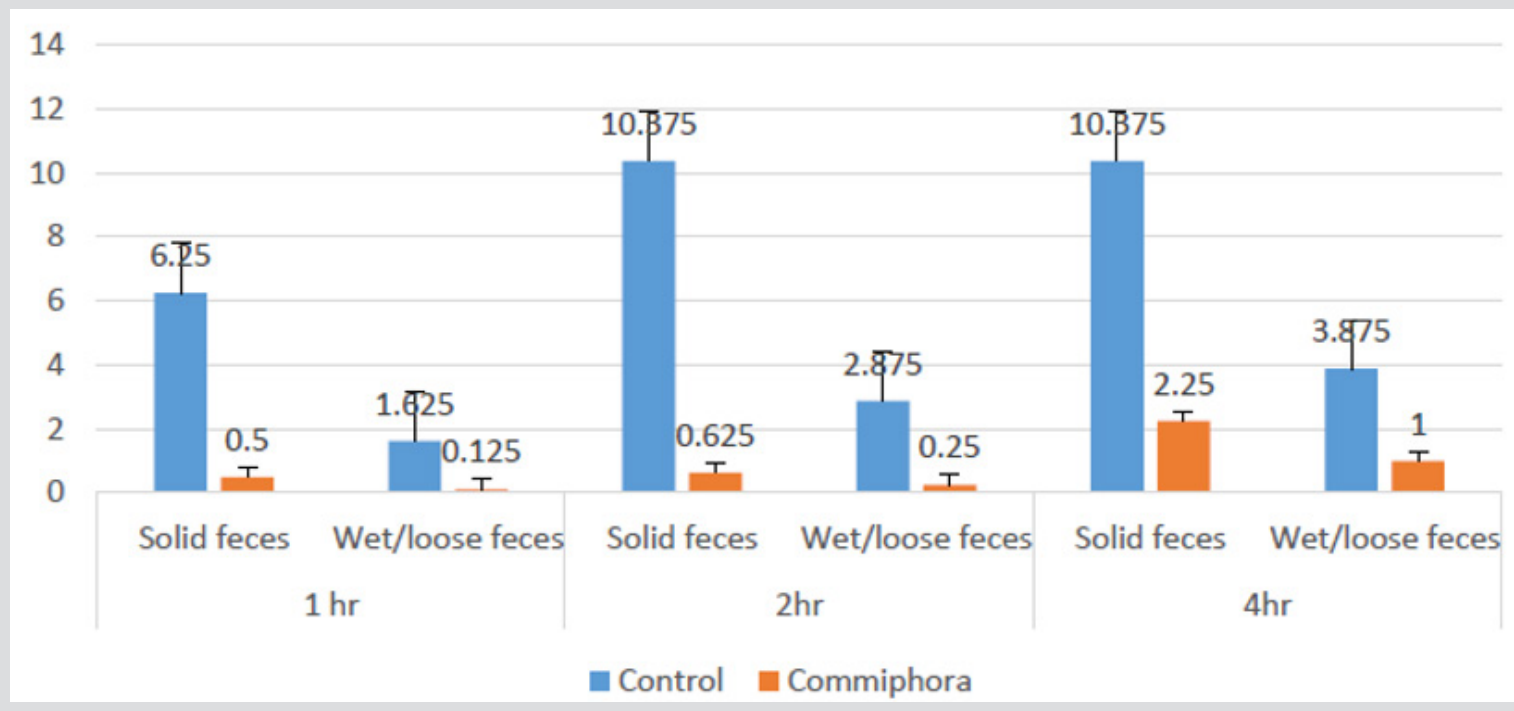

Figure 2: Anti-diarrhoeal activity of Commiphora myrrha on castor oil in mice model.

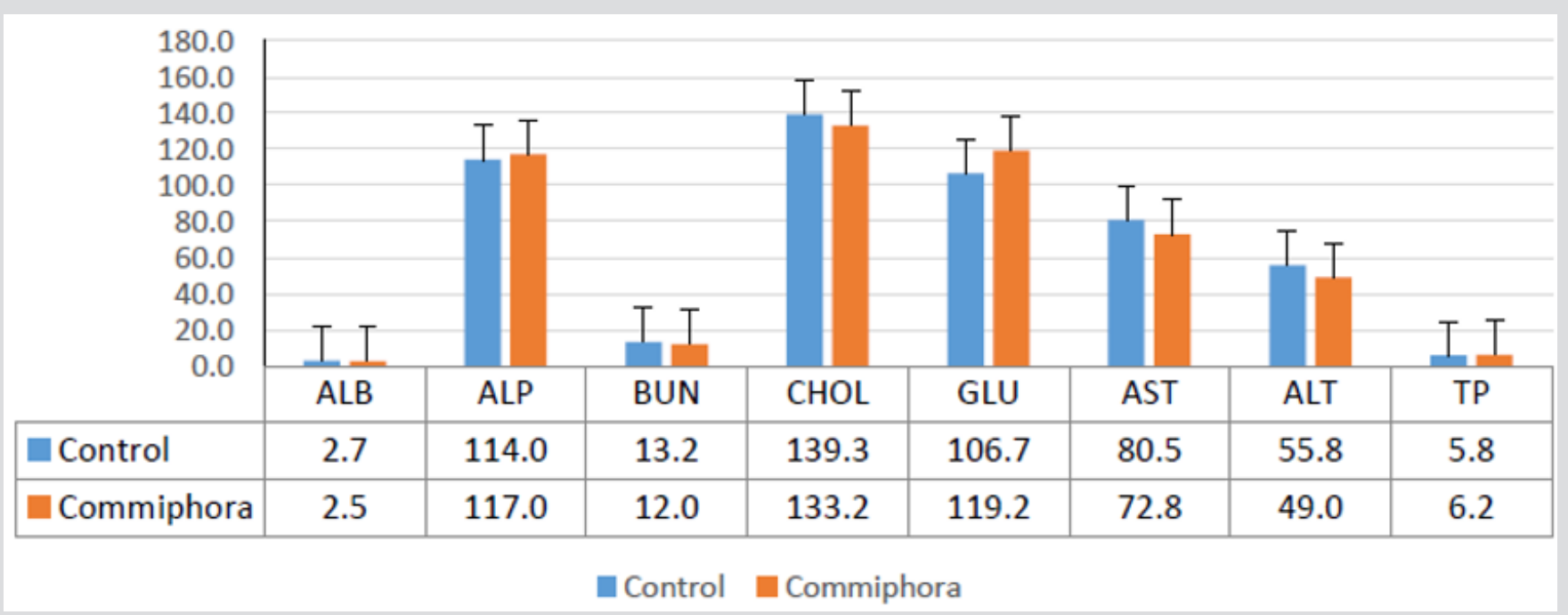

Figure 3: Biochemical study of Commiphora myrrah $1 \mathrm{~g} / \mathrm{kg} / 15$ days p.o. on SD rats.

\section{Hematological Studies:}

Commiphora myrrh did not exhibit any significant change on Hematological parameters (WBC, RBC, HGB, HCT, MCV, MCH, MCHC and PLT). Other than WBC that showed significant reduction (Figure 4).

\section{Anti-gastric Ulcer Activity:}

The Anti-gastric ulcer activity of Commiphora myrrah was studied using rats Phenylbutazone induced ulcer, showing positive therapeutic effect (Figure 5). 


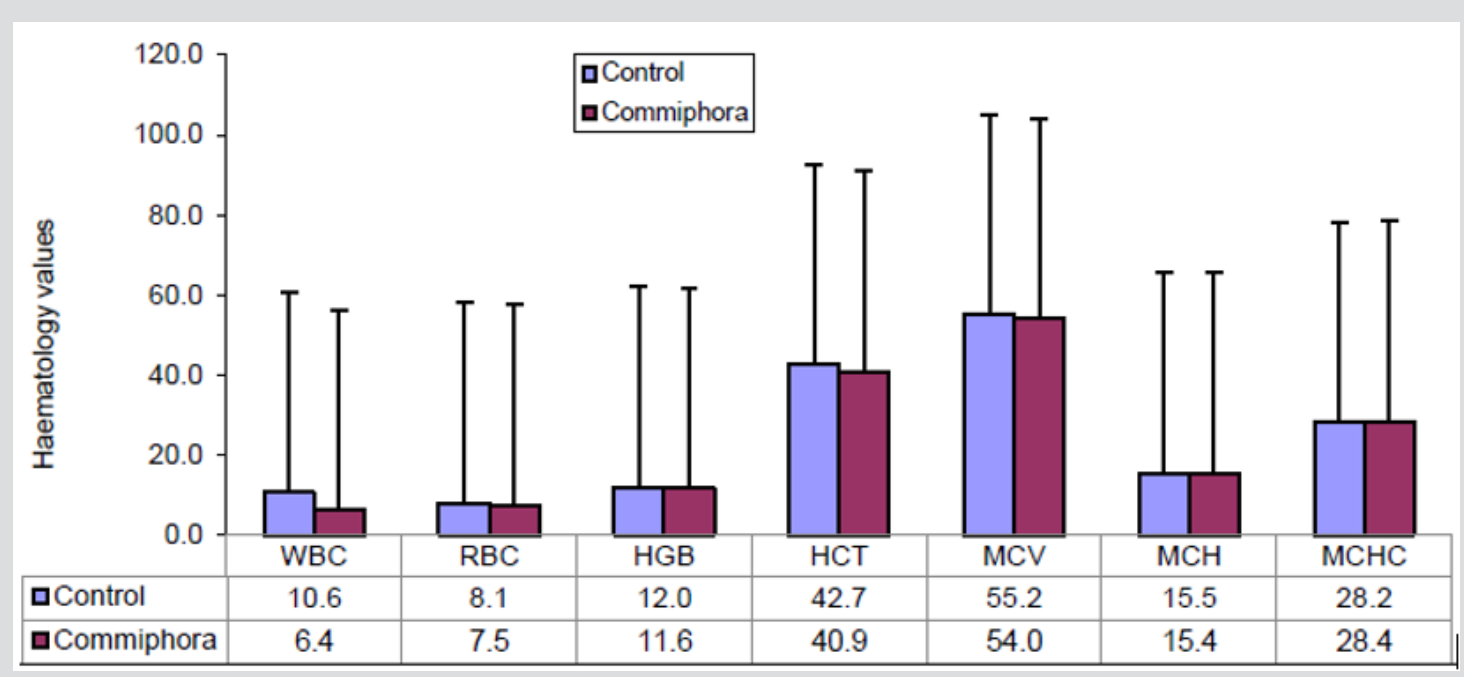

Figure 4: Haematological effect of Commiphora myrrah.

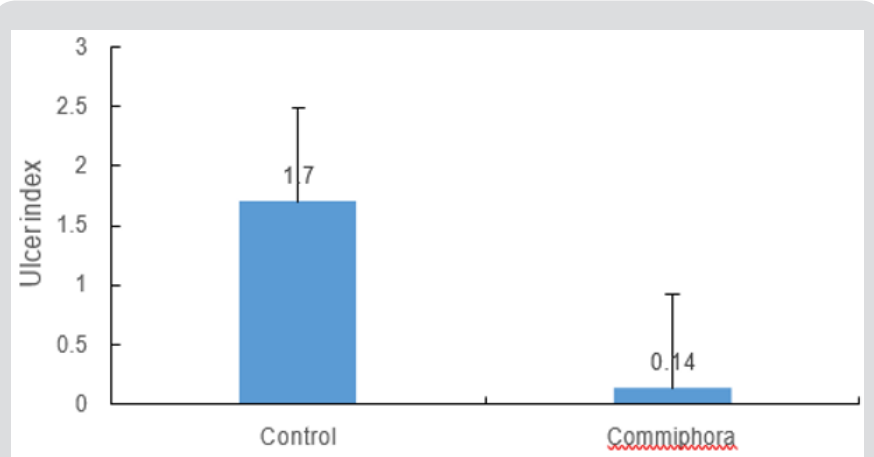

Figure 5: Anti-diarrhoeal activity of Commiphora myrrha on castor oil in mice model.

\section{Wound Healing Activity:}

The mixture of (Commiphora myrrah + Alovera) showed little improvement in the Wound healing activity but insignificant.

\section{Rabbit Jejunum:}

Spontaneous activity decreased moderately inhibited producing Anti-diarrheal effect (++). Mildly inhibited directly; moderately inhibited in the presence of ACH

\section{Guinea Pig Ileum:}

Relaxation showing Anti-diarrheal (+++), Relaxation (++) decreased the resting tension.

\section{ISSN: 2574-1241}

DOI: $10.26717 /$ BJSTR.2019.19.003306

Mohammad Kamil. Biomed J Sci \& Tech Res

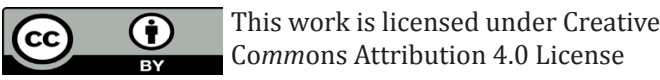

Submission Link: https://biomedres.us/submit-manuscript.php

\section{Rat atria:}

a) Force increased (+) Rate decreased (+).

b) Force increased (++++) Rate unchanged.

c) Force decreased (++) Rate decreased (+) Cardio-tonic.

\section{References}

1. FI Al-Jenoobi, A Ahad, M Raish, AM Al-Mohizea, MA Alam (2015) Investigating the Potential Effect of Commiphora myrrha on the Pharmacokinetics of Theophylline, a Narrow Therapeutic Index Drug. 1Department of Pharmaceutics, College of Pharmacy, King Saud University, Riyadh, Saudi Arabia, Drug Res (Stuttg) 65(6): 312-316.

2. Bhatia A, Bharti SK, Tripathi T, Mishra A, Sidhu OP, et al. (2015) Metabolic profiling of Commiphora wightii (guggul) reveals a potential source for pharmaceuticals and nutraceuticals. Phytochemistry 110: 29-36.

3. Suad A Gadir, Ibtisam M Ahmed (2014) Commiphora myrrha and Commiphora Africana essential oils. Journal of Chemical and Pharmaceutical Research, JCPRC 6(7): 151-156.

4. Ashry KM, El-Sayed YS, Khamiss RM, El-Ashmawy IM (2010) Oxidative stress and immunotoxic effects of lead and their amelioration with myrrh (Commiphora molmol) emulsion. Food Chem Toxicol 48(1): 236241.

5. Undercounting of agroforestry skews climate change mitigation planning and reporting, World Agroforestry.

6. ZCHRTM, Unpublished Results.

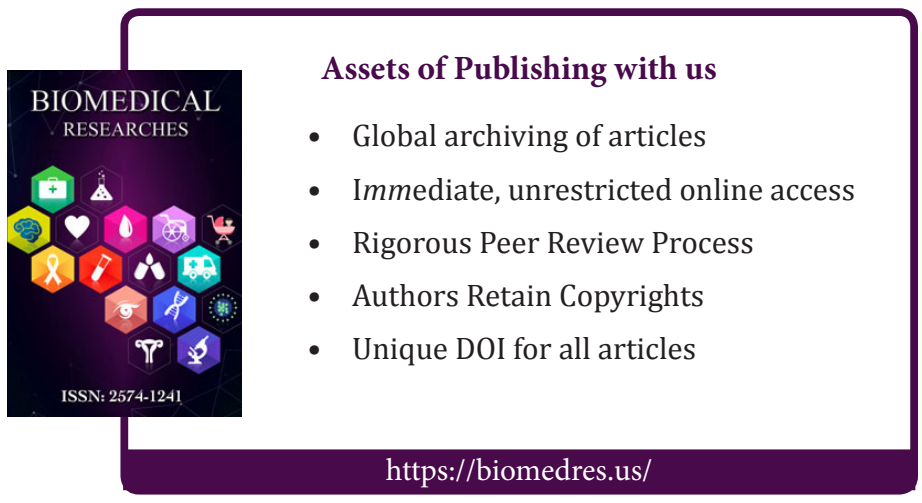

